\title{
ADEQUAÇÃO DA EVIDENCIAÇÃO SOCIAL DAS EMPRESAS DE CAPITAL ABERTO NO RELATÓRIO DA ADMINISTRAÇÃO E NOTAS EXPLICATIVAS ÀS RECOMENDAÇÕES DA NBC T 15
}

\section{ADEQUACY OF SOCIAL DISCLOSURE OF THE OPEN CAPITAL COMPANIES ON THE ADMINISTRATION REPORT AND EXPLANATORY NOTES TO THE NBC T 15 RECOMMENDATIONS}

\author{
ILSE MARIA BEUREN \\ Doutora em Controladoria e Contabilidade pela Universidade de São Paulo \\ Professora da Fundação Universidade Regional de Blumenau \\ Email: ilse@furb.br \\ JULIANE ELISABETH HORN \\ Universidade do Oeste de Santa Catarina - UNOESC
}

Resumo

\author{
MARINES LUCIA BOFF \\ Mestre em Ciências Contábeis pela Fundação Universidade Regional de Blumenau \\ Professora da Universidade do Oeste de Santa Catarina - SC, UNOESC - Santa \\ Catarina, SC - Brasil \\ E-mail: marinesboff@hotmail.com \\ MARCIANE ANGELA HORN \\ Universidade do Oeste de Santa Catarina - UNOESC \\ Email: jlklein@uol.com.br
}

\begin{abstract}
A NBC T 15, aprovada pela Resolução do CFC $n^{\circ} .1 .003 / 04$, normatiza os procedimentos para evidenciação de informações de natureza social e ambiental, que devem ser observados pelas empresas desde $1^{\circ}$ de janeiro de 2006. Assim, o estudo objetiva averiguar se a evidenciação social no relatório da administração e nas notas explicativas das empresas de capital aberto está adequada às recomendacões da NBC T 15, comparando o exercício social de 2005 , ano anterior, e o exercício social de 2007, ano posterior à entrada em vigor da referida norma. Para tanto, realizou-se pesquisa descritiva, por meio de pesquisa documental, com abordagem quantitativa. Analisaram-se os relatórios da administração e notas explicativas do período de 2005 a 2007 , das 23 empresas de capital aberto listadas na Revista Exame 150 Melhores Empresas para Você Trabalhar, edição especial 2007. Os resultados da pesquisa mostram que, quando analisada a categorização da evidenciação social das empresas, podendo ela ser de forma completa (IC), incompleta (II) ou ausente (IA), a última categoria predominou, usando como parâmetro o preconizado na NBC T 15. Comparando-se a pontuação da evidenciação social entre o ano de 2005 e 2007, constatou-se que dez empresas apresentaram acréscimo na sua pontuação final, enquanto sete apresentaram queda na sua pontuação final. Conclui-se, em relação ao nível de adequação da evidenciação social às recomendações da NBC T 15 , com base na análise dos relatórios da administração e notas explicativas no período de 2005 a 2007 das 23 empresas de capital aberto do estudo, que há predomínio da classificação regular, pois quatro empresas obtiveram conceito insuficiente de evidenciação, doze conceito regular, seis conceito bom e uma empresa obteve conceito ótimo.
\end{abstract}

Palavras-chave: evidenciação social; relatório da administração; notas explicativas; NBC T 15.

\section{Abstract}

The NBC T 15, approved by CFC Resolution from 1.003/04, standardizes the procedures for social and environmental information disclosure, to be followed by companies from January $1^{\text {st }} ., 2006$ on. Therefore, the study aims to verify if the social disclosure on the administration report and on the explanatory notes of open capital companies is adequate to the NBC T 15 recommendations, comparing the social practice of 2005, the year before, and the social practice of 2007, the year after the implementation of such resolution. Thus, a descriptive research was carried out through documental research, with quantitative approach. There had been analyzed the administration reports and explanatory notes of the period from 2005 to 2007, of 23 open capital companies, listed on the magazine Exame 150 Melhores Empresas Para Você Trabalhar, 2007 special edition. The survey results show that, when examining the categorization of companies' social disclosure, which could be $\mathrm{Cl}$ (complete information), II (incomplete information) or Al (absent information), the last category prevailed, using NBC $T 15$ as parameter. Comparing the social disclosure scores of the years 2005 and 2007, it was found that ten companies showed increase in their final score, while seven showed a decrease. Regarding to the social disclosure level of adequacy to the NBC T 15 recommendations, based on the analyses of the administration reports and explanatory notes in the period from 2005 to 2007 of the 23 open capital companies in this study, it is concluded that there is a predominance of regular classification, since four companies had insufficient disclosure qualification, twelve regular qualification, six good qualification and one company obtained great qualification.

Keywords: Social Disclosure. Administration Report. Explanatory Notes. NBC T 15. 


\section{INTRODUÇÃO}

No atual cenário empresarial de globalização e competição, "ser socialmente responsável nos negócios vem se tornando imprescindível para as empresas” (VELOSO, 2006, p. 2). Além da evidenciação econômico-financeira prevista na legislação, as empresas precisam demonstrar também suas ações no campo social, tornando público o comportamento empresarial consciente e responsável.

As empresas, além da preocupação com os lucros, crescimento da organização e conquista de novos mercados, necessitam cuidar da sua imagem diante da sociedade, particularmente no que tange a postura quanto ao desenvolvimento econômico e humano das pessoas que com elas se inter-relacionam. Não basta apenas contribuir, também é preciso apresentar atitudes e práticas efetivas nesse sentido.

Quando as empresas disponibilizam informações verídicas e transparentes da conduta e de seu papel social enquanto organização com fins lucrativos, tornam-se relevantes e diferenciadas das demais empresas presentes no mercado. Transmitem segurança e impulsionam investimentos com menor grau de risco, com sustentabilidade e probabilidade de maior valorização e competitividade, o que garante a permanência e sobrevivência no mercado competitivo.

Segundo Parsa e Kouhy (2001), as empresas evidenciam informações sociais para promoverem informações sobre suas atividades, visando legitimar seus comportamentos e ações, assim como projetar seus valores e suas idéias em resposta a fatores externos. Por meio da divulgação de informações de caráter econômico, financeiro, patrimonial, e agora, de natureza social, a qual se apresenta como diferencial nas demonstrações publicadas, os usuários serão providos de informações mais completas para analisar o comportamento da organização. Estes usuários podem identificar ações sociais que mostram o papel da empresa como agente participativo e preocupado com a evolução de todos os elementos da sociedade.

A NBC T 15 - Informações de Natureza Social e Ambiental, aprovada pela Resolução CFC $n^{\circ}$. 1.003/04, estabelece os elementos de evidenciação das informações de natureza social e ambiental, com o objetivo de demonstrar à sociedade a participação e a responsabilidade social da entidade. Porém, "é factível que parcela considerável de gestores possam demonstrar resistências diante da perspectiva da divulgação de indicadores que sugerem fraquezas organizacionais" (MAZZIONI; TINOCO, 2005, p. 15). Assim, para diversas empresas, pode ser inviável evidenciar informações de natureza social e ambiental que venham a manchar sua imagem perante a sociedade.

Neste sentido, estudos acerca da evidenciação social e ambiental em demonstrativos contábeis vêm crescendo, tanto em âmbito nacional, como 
internacional. Alguns dos estudos sobre evidenciação social são aqui citados, como de Deegan, Rankin e Tobin (2002), Dalmácio e Paulo (2004), Gao, Heravi e Xiao (2005), Faria e Oliveira (2006), Sancovschi e Silva (2006), Vieira (2006), Vieira e Faria (2007), Beuren e Boff (2009), Cavalcanti et al. (2009), Faria e Pereira (2009).

Com base no exposto, elaborou-se a seguinte questão-problema: a evidenciação social no relatório da administração e notas explicativas das empresas de capital aberto está adequada às recomendações da NBC T 15, comparando-se o exercício social de 2005, ano anterior, e o exercício social de 2007, ano posterior a entrada em vigor da referida norma? O objetivo geral do estudo é averiguar se a evidenciação social no relatório da administração e notas explicativas das empresas de capital aberto está adequada às recomendações da NBC T 15, comparando-se o exercício social de 2005, ano anterior, e o exercício social de 2007, ano posterior a entrada em vigor da referida norma.

Considerando a questão-problema e o objetivo geral do estudo, formularam-se os seguintes objetivos específicos: a) caracterizar as empresas pesquisadas, dentre as listadas na Revista Exame 150 Melhores Empresas para Você Trabalhar, edição especial 2007; b) categorizar a evidenciação social destas empresas segundo um checklist, baseado na NBC T15; e c) classificar a evidenciação social no relatório da administração e notas explicativas das empresas pesquisadas.

Destaca-se a relevância do presente estudo, norteado pela NBC T 15, que normatiza os procedimentos para evidenciação de informações de natureza social e ambiental. A norma citada foi aprovada pela Resolução $n^{\circ}$. 1.003/04, e entrou em vigor em $1^{\circ}$ de janeiro de 2006. Sendo assim, é mandatório verificar se após essa resolução as empresas estão se adequando às normas brasileiras de contabilidade, especificamente à NBC T 15, instituída pelo Conselho Federal de Contabilidade (CFC).

\section{FUNDAMENTAÇÃO TEÓRICA}

Decidir quanto e quais informações devem ser disponibilizadas ao público, por meio dos demonstrativos contábeis, tem sido um desafio para as empresas diante de uma sociedade mais questionadora sobre as questões ambientais e sociais relacionadas direta e indiretamente com os seus negócios. Dalmácio e Paulo (2004, p. 7) destacam que "os usuários precisam e procuram, nos demonstrativos contábeis publicados, informações sociais sobre a empresa". Porém, a sociedade somente terá conhecimento de tais informações se as empresas estiverem comprometidas com a transparência, tempestividade e veracidade de sua situação e atitude perante os aspectos sociais e ambientais que envolvem, simultaneamente, ela e a sociedade. 
Tal questão acentua-se pelo fato de as atenções estarem voltadas às atitudes, ética e responsável, das organizações perante a sociedade, o meio ambiente e seus colaboradores, levando as organizações a refletirem sobre suas atitudes diante deste cenário. DiMaggio e Powell (2005, p. 77) salientam que "as organizações não competem somente por recursos e clientes, mas por poder político e legitimação institucional, por adequação social, assim como por adequação econômica". Lindblom (1994) ressalta que a legitimidade organizacional está relacionada ao desempenho social e na divulgação de tal desempenho. A busca pela legitimidade organizacional influencia a forma e o conteúdo da evidenciação social corporativa.

As empresas possuem um compromisso social com a sociedade, não devendo mais almejar somente o lucro. É necessário que exista um relacionamento de respeito no aspecto social, pois as empresas tornaram-se peças fundamentais para o desenvolvimento econômico e social da nação. A contabilidade, como ciência social, visa atender amplamente as necessidades informacionais de seus usuários. Disponibiliza um conjunto de demonstrativos contábeis de caráter quantitativo e qualitativo, para divulgar além da situação econômica, financeira e patrimonial da empresa, o seu relacionamento com o meio ambiente e o social, independentemente de exigências legais.

O Conselho Federal de Contabilidade (CFC), por meio da Resolução n 1.003/04, aprovou em 19 de agosto de 2004 a NBC T 15 - Informações de Natureza Social e Ambiental. Essa norma estabelece os elementos de evidenciação das informações de natureza social e ambiental, com o objetivo de demonstrar à sociedade a participação e responsabilidade social e ambiental das empresas. De acordo com o item 15.1.2 da NBC T 15, "entende-se por informações de natureza social e ambiental: a) a geração e a distribuição de riqueza; b) os recursos humanos; c) a interação da entidade com o ambiente externo; d) a interação com o meio ambiente".

A norma estabelece que tais informações, quando divulgadas, devem ser entendidas como informação complementar às demonstrações contábeis, não se confundindo com as notas explicativas. Mesmo que a empresa divulgue as informações supracitadas nas notas explicativas ou no relatório da administração, ela precisa divulgá-las, também, em outro demonstrativo complementar, denominado Demonstração de Informações de Natureza Social e Ambiental.

No item 15.2 da NBC T 15 são especificadas as informações a serem divulgadas no que concerne à Geração e Distribuição de Riqueza; Recursos Humanos; Interação da Entidade com o Ambiente Externo; e Interação com o Meio Ambiente. A NBC T 15 esclarece que a entidade poderá acrescentar ou detalhar outras informações que julgar relevante além daquelas dispostas no item 15.2. Também prevê que a Demonstração de Informações de Natureza Social e Ambiental deve ser objeto de auditoria independente quando a empresa for submetida a tal processo.

O IASB determina na norma IAS 8 que a administração da empresa deverá seguir 
os requisitos recomendados nessa norma para divulgar informações relevantes aos usuários das demonstrações contábeis. Acrescenta que, "na ausência de uma norma ou interpretação específica, a administração deve utilizar-se de seu julgamento para desenvolver e aplicar políticas contábeis que sejam relevantes para os usuários das demonstrações contábeis, e confiáveis no contexto das demonstrações como um todo".

Denota-se que, mesmo na ausência de uma norma ou lei que estabeleça ou regulamente a divulgação de informações que sejam relevantes aos usuários das demonstrações contábeis, a administração da empresa não pode deixar de reconhecer e divulgar tais informações. Rover, Alves e Borba (2005, p. 1) explicam que a evidenciação “é entendida como a maneira pela qual a informação é apresentada”. Assim, a evidenciação contábil, seja ela de natureza quantitativa ou qualitativa, se apresenta com objetivos e maneiras pré-definidas, que variam de acordo com as necessidades do emissor e do receptor.

É perceptível a tendência cada vez maior das empresas valorizarem a divulgação de informações de cunho ambiental e social. Gao, Heravi e Xiao (2005, p. 234) enfatizam que "a evidenciação ambiental e social corporativa tem atraído consideravelmente pesquisas acadêmicas desde os anos de 1980”. Nesse sentido, Dias Filho (2007, p. 2) destaca que "essa percepção tem levado a comunidade científica da área contábil a investigar as razões pelas quais determinadas empresas resolvem expandir suas evidenciações independentemente de exigência legal”.

Algumas dessas pesquisas são citadas para ilustrar o interesse de acadêmicos em estudos dessa natureza. Deegan, Rankin e Tobin (2002) analisaram os relatórios anuais de uma das maiores empresas australianas no período de 1983 a 1997, cujo objetivo era analisar se a evidenciação ambiental e social apresentava relação com a teoria da legitimidade. Verificaram um crescente e constante aumento de informações ambientais e sociais com o passar dos anos, sem padrão na evidenciação.

Dalmácio e Paulo (2004) buscaram identificar qual a forma mais eficiente de evidenciação da informação contábil, que poderia facilitar a compreensão e a interpretação de aspectos sócio-ambientais e econômico-financeiros. Os autores realizaram uma pesquisa nas demonstrações contábeis de empresas industriais, sociedades anônimas, do Estado do Espírito Santo, referentes ao exercício de 2002 e constataram que a evidenciação oscilou entre as Notas Explicativas e o Relatório da Administração, sendo que este se mostrou mais flexível e interessante para os usuários externos, levando-se em consideração as proxies utilizadas.

Gao, Heravi e Xiao (2005) analisaram 154 relatórios anuais de 33 companhias de Hong Kong no período de 1993 a 1997, visando identificar as determinantes da quantidade da evidenciação ambiental e social corporativa. Os resultados encontrados indicaram que existem diferenças na quantidade, tema e posição da evidenciação nos relatórios anuais entre as indústrias. Pela correlação positiva, concluíram que 
o tamanho da companhia influencia o nível da evidenciação ambiental e social corporativa.

A NBC T 15, do Conselho Federal de Contabilidade (CFC), foi utilizada como base na pesquisa de Faria e Oliveira (2006), em que buscaram verificar como têm sido evidenciados os investimentos, passivos e custos ambientais por empresas do ramo químico e petroquímico. Os autores constataram que as demonstrações contábeis das empresas analisadas mostraram-se pouco adequadas às necessidades dos usuários da informação contábil, pois, dentre sete empresas, apenas uma teve sua evidenciação classificada como "bem adequada" às exigências da referida norma.

Sancovschi e Silva (2006) analisaram a forma que a empresa Petróleo Brasileiro S.A. utilizou para evidenciar voluntariamente as informações sociais em seus relatórios anuais, no período de 1993 a 2002. Eles constataram que a empresa utilizou determinadas estratégias de evidenciação de informações sociais, como argumentos em benefício próprio na explicação dos problemas relacionados às atividades da empresa. Os administradores da empresa concentram-se em apresentar informações sociais que enfatizam aspectos positivos em detrimento dos negativos.

Vieira (2006) objetivou verificar se a maior empresa em cada segmento da economia brasileira evidencia, de maneira adequada, informações de responsabilidade social. Ele constatou que três empresas apresentaram conceito péssimo no que concerne à evidenciação de informações de responsabilidade social, quatro, conceitos Ótimo, e outras com conceito Bom ou Regular. Concluiu que, apesar da escassez de normas sobre evidenciação da responsabilidade social, mesmo não apresentando as informações relacionadas com clareza, as empresas pesquisadas demonstraram preocupação com a questão social.

Baseando-se nas recomendações da NBC T 15 quanto à evidenciação de informações de responsabilidade social, Vieira e Faria (2007) objetivaram verificar se, em 2005, as 14 maiores empresas por faturamento no segmento de alimentos e bebidas da economia brasileira evidenciaram, de maneira adequada, informações de responsabilidade social. Constataram que cinco empresas mostraram um Péssimo conceito; quatro apresentaram Ótimo desempenho na evidenciação de suas informações de responsabilidade social; e outras se apresentaram de forma Boa ou Regular.

Beuren e Boff (2009) objetivaram verificar a tendência dos termos ambientais e sociais evidenciados nos relatórios da administração de 1997 a 2006 de 16 empresas familiares brasileiras. Constataram aumento da evidenciação social a cada ano, direcionada, principalmente, a dois públicos diferentes das empresas, o público interno e o público externo, com predomínio de informações sociais diante das ambientais.

Além disso, os autores perceberam que as empresas têm enfatizado mais nos 
últimos anos as premiações e homenagens recebidas de instituições legitimadas na sociedade, como forma de reconhecimento pelas ações ambientais e sociais desenvolvidas.

Cavalcanti et al. (2009) objetivaram analisar se as informações contábeis ambientais divulgadas em 2007 por 42 empresas brasileiras do setor de utilidade pública cadastradas na Bovespa, em seus Balanços Sociais, atendiam às exigências da NBC-T 15. Concluíram que as informações contábeis ambientais divulgadas em seus Balanços Sociais apresentaram aderência parcial às exigências da NBC-T 15. Apenas $32 \%$, em média, das empresas estudadas evidenciaram as informações solicitadas por esta norma, enquanto $68 \%$ das empresas não as divulgaram, seja por não se enquadrarem na situação específica ou por omissão.

O estudo de Faria e Pereira (2009) objetivou analisar, por meio de pesquisa documental e análise de conteúdo, as informações socioambientais das maiores empresas por receita operacional bruta do segmento químico e petroquímico no Brasil, dos anos de 2006 e 2007. O objetivo foi verificar se essas empresas estão evidenciando as referidas informações de acordo com a Norma Brasileira de Contabilidade - NBC T15, que entrou em vigor em 2006. Os resultados demonstraram que as empresas Bayer e a Dow Química, apresentaram nível de evidenciação ruim, enquanto as outras apresentaram nível regular.

Considerando-se os estudos expostos, esta pesquisa busca avançar no sentido de comparar a evidenciação anterior e posterior a data de vigência da NBC T15 do CFC nos relatórios da administração e notas explicativas das demonstrações contábeis das empresas que constituem a amostra da pesquisa. Também inova no sentido de buscar um refinamento para os dados coletados na análise de conteúdo dos termos sociais, criando categorias relacionadas à completude das informações sociais evidenciadas.

\section{MÉTODO E PROCEDIMENTOS DA PESQUISA}

Esta pesquisa tem caráter descritivo e foi realizada por meio de pesquisa documental, com abordagem quantitativa dos dados. O caráter descritivo decorre do fato de se analisar e classificar as características da evidenciação social das empresas. Gil (2002, p. 42) destaca que "as pesquisas descritivas têm como objetivo primordial a descrição das características de determinada população ou fenômeno ou, então, o estabelecimento de relações entre variáveis”.

$\mathrm{Na}$ pesquisa documental investigaram-se os relatórios da administração e as notas explicativas do período de 2005 a 2007 das 23 empresas de capital aberto, listadas na Revista Exame 150 Melhores Empresas para Você Trabalhar, edição 
especial 2007. A escolha da Revista Você S/A - Exame - As Melhores Empresas para Você Trabalhar 2007, se deu pelo fato de ela selecionar as 150 melhores empresas que alcançaram esse nível de desempenho investindo no ambiente de trabalho. São premiadas aquelas empresas que têm o melhor conjunto de iniciativas em estratégia e gestão, saúde, remuneração, cidadania empresarial, diversidade, desenvolvimento e liderança.

Para a coleta dos dados, o estudo baseou-se no checklist de Vieira (2006), o qual possibilitou atribuir uma classificação às empresas analisadas quanto à evidenciação social. Optou-se pelo checklist, por se tratar de um roteiro de itens ou características a serem verificadas quanto à evidenciação social, propiciando identificar a adequação das empresas à NBC T 15, observando os procedimentos estabelecidos nesta norma. No Quadro 1 apresenta-se o checklist das informações consideradas na pesquisa documental.

\begin{tabular}{|c|}
\hline ... publica o Balanço Social? \\
\hline ... publica a DVA? \\
\hline $\begin{array}{l}\text {... evidencia no relatório da administração e/ou nas notas explicativas dados referentes à remune- } \\
\text { ração, benefícios concedidos, composição do corpo funcional, contingências e passivos trabalhistas } \\
\text { da entidade? }\end{array}$ \\
\hline $\begin{array}{l}\text {... evidencia no relatório da administração e/ou nas notas explicativas dados relativos à interação } \\
\text { da entidade com o ambiente externo e relacionamento com a comunidade, clientes, fornecedores } \\
\text { e incentivos decorrentes dessa interação? }\end{array}$ \\
\hline ... utiliza critérios de responsabilidade social para a seleção de fornecedores? \\
\hline $\begin{array}{l}\text {... evidencia a remuneração bruta segregada por empregados, administradores, terceirizados e } \\
\text { autônomos? }\end{array}$ \\
\hline ... evidencia gastos com previdência privada? \\
\hline ... evidencia gastos com cultura, seja com seu público interno quanto externo? \\
\hline ... evidencia participação dos funcionários nos resultados? \\
\hline ... evidencia informações relativas a ações trabalhistas? \\
\hline ... evidencia valor de indenizações e multas pagas por determinação da justiça a empregados? \\
\hline ... evidencia investimentos em educação? \\
\hline $\begin{array}{l}\text {... evidencia o número de reclamações recebidas por meio dos órgãos de proteção e defesa do } \\
\text { consumidor? }\end{array}$ \\
\hline
\end{tabular}

Quadro 1 - Checklist das informações consideradas na pesquisa documental Fonte: adaptado de Vieira (2006, p. 55).

Visando responder aos objetivos propostos, inicialmente fez-se a contagem das informações de cunho social evidenciadas pelas empresas em seus relatórios da administração e notas explicativas no decorrer dos três anos analisados. Assim efetuou-se o preenchimento por empresa da presença ou não das informações predeterminadas no checklist formulado de acordo com a NBC T 15.

Buscaram-se 13 informações em cada ano (2005, 2006 e 2007) nos relatórios da administração e notas explicativas das 23 empresas analisadas, totalizando 39 informações que cada empresa poderia apresentar de forma completa, incompleta ou ausente no período analisado. 
Gamboa (1995, p. 106) menciona que, ao "inserirmos os dados na dinâmica da evolução do fenômeno e este, dentro de um todo maior compreensivo, é preciso articular as dimensões qualitativas e quantitativas em uma inter-relação dinâmica, como categorias utilizadas pelo sujeito na explicação e compreensão do objeto". Nesta perspectiva, de acordo com a evidenciação das informações consideradas na pesquisa e disponibilizadas pelas empresas, categorizaram-se as evidenciações em informação completa (IC), informação incompleta (II) e informação ausente (IA), conforme se demonstra no Quadro 2.

\begin{tabular}{|c|l|lc|c|}
\hline Categorias & Posição & Significado & Pesos \\
\hline IC & $\begin{array}{l}\text { Informação } \\
\text { Completa }\end{array}$ & $\begin{array}{l}\text { A informação prevista encontra-se presente e completa no } \\
\text { relatório da administração ou nas notas explicativas. }\end{array}$ & 5 \\
\hline II & $\begin{array}{l}\text { Informação } \\
\text { Incompleta }\end{array}$ & $\begin{array}{l}\text { Ainformação prevista encontra-se no relatório da administração } \\
\text { ou nas notas explicativas, porém, de maneira incompleta, } \\
\text { deficitária }\end{array}$ & 3 \\
\hline IA & $\begin{array}{l}\text { Informação } \\
\text { Ausente }\end{array}$ & $\begin{array}{l}\text { A informação prevista não se encontra no relatório da } \\
\text { administração e nas notas explicativas. }\end{array}$ & 1 \\
\hline
\end{tabular}

Quadro 2 - Categorias da qualidade das informações

Fonte: adaptado de Beuren, Boff e Hein (2008).

$\mathrm{Na}$ sequência, multiplicando-se a quantidade de informações sociais do checklist evidenciadas por empresa com seu respectivo peso $(I C=5 ; I I=3$ e $I A=1)$, obteve-se a pontuação final de cada empresa. Como exemplo, uma empresa que apresente durante o período de três anos 39 informações, distribuídas em 13 IC, 13 II e 13 IA, essas quantidades the dariam uma pontuação final de 117 pontos $(13 \times 5 ; 13 \times 3$; $13 \times 1=117)$. Após a categorização da evidenciação e atribuição da pontuação para cada uma das empresas, a pontuação obtida por elas foi classificada em Insuficiente, Regular, Boa e Ótima, considerando a menor e a maior pontuação, conforme exposto no Quadro 3.

\begin{tabular}{|c|c|}
\hline Pontuação final & Classificação da evidenciação \\
\hline 39 a 78 pontos & Insuficiente \\
\hline 79 a 117 pontos & Regular \\
\hline 118 a 156 pontos & Boa \\
\hline 158 a 195 pontos & Ótima \\
\hline
\end{tabular}

Quadro 3 - Classificação da evidenciação social

Fonte: elaboração própria.

Com base no critério estabelecido, durante os três anos analisados, o mínimo

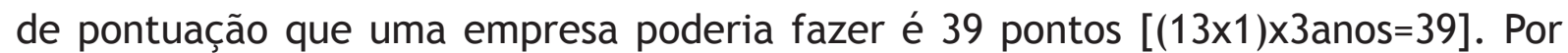

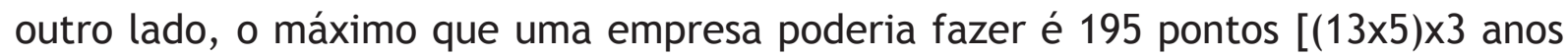
=195]. A principal limitação da pesquisa deve-se ao fato de serem analisados somente o relatório da administração e as notas explicativas, não havendo uma verificação in loco de outros possíveis meios de evidenciação social. Outra limitação do estudo diz respeito à subjetividade presente na análise documental, que envolve interpretações e decodificações pessoais por parte do pesquisador. Em virtude disso, deve-se levar em consideração a subjetividade decorrente das inferências particulares no decorrer da análise dos dados. 


\section{DESCRIÇÃO E ANÁLISE DOS DADOS}

Nesta seção faz-se a descrição e análise dos dados. Inicia-se com a caracterização das empresas pesquisadas. Na sequência, apresenta-se a categorização da evidenciação social das empresas no período de 2005 a 2007. Segue a comparação do nível de pontuação da evidenciação social considerando-se o ano de 2005 (período anterior) e o ano 2007 (período posterior) da entrada em vigor da NBC T 15. Por fim, demonstra-se a classificação da evidenciação social das empresas no período de 2005 a 2007.

\subsection{CARACTERIZAÇÃO DAS EMPRESAS PESQUISADAS}

Sobre a caracterização das empresas pesquisadas de capital aberto, listadas na Revista Exame 150 Melhores Empresas para Você Trabalhar, edição especial 2007, inicia-se apresentando as empresas participantes da pesquisa, com destaque à razão social, ao nome fantasia e ao ano de fundação. Após, apresentam-se o ramo de atividade das empresas na economia brasileira e o número de funcionários. Na Tabela 1 apresenta-se a razão social das empresas pesquisadas, o nome fantasia e os seus respectivos anos de fundação.

Tabela 1 - Razão social e ano de fundação das empresas

\begin{tabular}{ccc}
\hline Razão social & Nome fantasia & Ano de fundação \\
\hline AES Sul Distribuidora Gaúcha de Energia S.A. & AES Sul & 1996 \\
AES Tietê S.A. & AES Tietê & 1999 \\
Companhia de Bebidas das Américas & Ambev & 2000 \\
Ampla Energia e Serviços S.A. & Ampla & 1996 \\
Aracruz Celulose S.A. & Aracruz & 1972 \\
Banco Industrial e Comercial S.A. & Bic Banco & 1938 \\
Banco Bradesco S.A. & Bradesco & 1943 \\
Braskem S.A. & Braskem & 2002 \\
Cia Energética de Minas Gerais & Cemig & 1952 \\
Cia Energética do Ceará & Coelce & 1971 \\
CPFL Geração de Energia S.A. & CPFL Energia & 2000 \\
Datasul S.A. & Datasul & 1978 \\
Fras-le S.A. & Fras-le & 1959 \\
Lojas Renner S.A. & Lojas Renner & 1966 \\
Marcopolo S.A. & Marcopolo & 1949 \\
Natura Cosméticos S.A. & Natura & 1969 \\
Odontoprev S.A & Odontoprev & 1987 \\
Plascar Participações Industriais S.A. & Plascar & 1963 \\
Souza Cruz S.A. & Souza Cruz & 1903 \\
Springer S.A. & Springer Carrier & 1969 \\
Wriban S.A & Unibanco & 1967 \\
Whirlpool S.A. & Weg & 1969 \\
\hline
\end{tabular}

Fonte: sítio da Bovespa e das empresas.

Verifica-se na Tabela 1 que dentre as empresas pesquisadas, a empresa Souza Cruz destaca-se em tempo de atividade, fundada em 1903, seguida pela Bic Banco, fundada no ano de 1938. Apenas duas empresas tiveram sua inclusão no mercado 
na década de 1940, sendo elas, o Banco Bradesco em 1943 e a Marcopolo no ano de 1949. Nos anos de 1950, duas das empresas analisadas iniciaram suas atividades, a Cemig, fundada em 1952, e a Fras-le, em 1959.

De outro lado, seis empresas foram fundadas na década de 1960, sendo elas, Plascar (1963), Lojas Renner (1966), Unibanco (1967) e Natura, Springer Carrier e Weg (1969).

$\mathrm{Na}$ década de 1970 iniciaram suas atividades as empresas Coelce (1971), Aracruz (1972) e Datasul (1978), sendo que a empresa Odontoprev (1987) é a única empresa, dentre as analisadas, que iniciou suas operações na década de 1980. Já na década de 1990 iniciaram suas atividades três empresas, sendo elas, AES Sul e a Ampla (1996) e AES Tietê (1999).

Os anos 2000 foram marcados pela fundação das quatro empresas restantes. A Ambev e CPFL em 2000, seguidas pela Braskem em 2002 e a Whirlpool fundada em 2006, destacando-se como a empresa mais nova no mercado. Considerando-se as 23 empresas analisadas, verifica-se que metade delas tem mais de 40 anos de atividades, com destaque à empresa Souza Cruz, única centenária. A outra metade das empresas pesquisadas varia entre 23 e 4 anos de atividades no mercado. Apresentam-se no Quadro 4 as empresas participantes da pesquisa, seus respectivos ramos de atividade e o número de funcionários.

\begin{tabular}{|c|c|c|}
\hline Empresas & Ramo de atividade & N.funcionários \\
\hline AES Sul & Energia Elétrica - Distribuição & 893 \\
\hline AES Tietê & Energia Elétrica - Geração & 283 \\
\hline Ampla & Energia Elétrica - Produção, distribuição e comércio & 8.652 \\
\hline Cemig & Energia Elétrica - Concessionária de serviço público & 10.818 \\
\hline Coelce & Energia Elétrica - Venda & 1.297 \\
\hline CPFL Energia & Energia Elétrica - Serviços públicos de geração & 240 \\
\hline Bic Banco & Instituição financeira & 823 \\
\hline Bradesco & Instituição financeira & 82.773 \\
\hline Unibanco & Instituição financeira & 34.215 \\
\hline Springer Carrier & $\begin{array}{l}\text { Eletrodomésticos - indústria, comércio, importação e } \\
\text { exportacao }\end{array}$ & 828 \\
\hline Whirlpool & $\begin{array}{l}\text { Eletrodomesticos e compressores - produção e } \\
\text { comercializacão }\end{array}$ & 18.000 \\
\hline Ambev & Fabricação de cervejas e refrigerantes & 37.299 \\
\hline Aracruz & Produção de celulose de fibra branqueada de eucalipto & 2.495 \\
\hline Braskem & Indústria petroquímica & 3.427 \\
\hline Datasul & Exploração comercial de programas de computadores & 3.407 \\
\hline Fras-le & Indústria de auto peças e materiais de fricção & 2.500 \\
\hline Lojas Renner & Loja de departamentos - comércio varejista & 9.183 \\
\hline Marcopolo & Fabricação de carrocerias & 12.311 \\
\hline Natura & $\begin{array}{l}\text { Desenvolyimento, industrialização, distribuição } \\
\text { comercialização, de cosmetticos, fragrâncias em geral e } \\
\text { produtos de higiene pessoal }\end{array}$ & 5.919 \\
\hline Odontoprev & Operadora de planos odontológicos & 781 \\
\hline Plascar & Participação em outras empresas & 2.929 \\
\hline Souza Cruz & Fabricação de cigarros e exportação de fumo & 6.700 \\
\hline Weg & Mecânica & 19.956 \\
\hline
\end{tabular}

Quadro 4 - Ramo de atividade e número de funcionários das empresas

Fonte: Sítio da Bovespa e das empresas.

Quanto ao ramo de atividade, verifica-se no Quadro 4, que seis empresas, 
correspondendo a 26,1\% da amostra, pertencem ao ramo de energia elétrica, tanto na geração, quanto na distribuição e comércio de energia. No ramo das instituições financeiras concentra-se $13 \%$ da amostra, três empresas apenas. Quanto às empresas que se destinam ao ramo de indústria e comércio de eletrodomésticos, constam duas empresas, perfazendo $8,7 \%$ da amostra. As demais empresas analisadas compreendem ramos de atividades distintos, somando, no total, 12 empresas, que representam $52,2 \%$ das empresas analisadas.

Quanto ao número de funcionários, constata-se que seis empresas possuem menos de 1.000 funcionários, quatro empresas possuem entre 1.000 e 3.000 funcionários, três empresas possuem entre 3.000 e 6.000 funcionários, três empresas possuem de 6 mil a 10 mil funcionários, quatro empresas possuem de 10 a 20 mil funcionários, duas empresas possuem de 20 a 40 mil funcionários e somente uma empresa possui mais de 80 mil funcionários. Portanto, das 23 empresas, 17 (73,9\%) possuem entre 240 e 10.818 funcionários, enquanto as demais seis empresas $(26,1 \%)$ possuem entre 12.311 e 82.773 funcionários diretos.

Analisando-se especificamente o ramo de energia elétrica, constata-se que este emprega 22.183 funcionários, o que representa 8,3\% do número total de funcionários da amostra de 23 empresas. Dentro deste percentual, encontra-se a empresa Cemig, fundada em 1952 (mais antiga no ramo) que possui 10.818 funcionários, enquanto que a empresa CPFL, fundada em 2000 (mais nova no ramo), possui apenas 240 funcionários.

Considerando-se somente as instituições financeiras, constata-se que este ramo de atividade é o que mais emprega, já que apenas três empresas (Bic Banco, Bradesco e Unibanco) empregam no conjunto 117.811 funcionários, enquanto toda a amostra emprega 265.729 funcionários, ou seja, as instituições financeiras deste estudo concentram $44,4 \%$ do total empregado nas 23 empresas.

\subsection{CATEGORIZAÇÃO DA EVIDENCIAÇÃO SOCIAL DAS EMPRESAS}

Para a categorização da evidenciação social das empresas, buscaram-se no relatório da administração e notas explicativas 13 informações para cada ano analisado, isto é, cada empresa apresentou o total de 39 informações distribuídas nas categorias IC, II e IA.

Apresentam-se os resultados na Tabela 2, referente à pontuação final obtida por empresa no período analisado, que compreendeu 2005, 2006 e 2007. 
Tabela 2 - Categorização da evidenciação social das empresas

\begin{tabular}{lcccc}
\hline \multicolumn{1}{c}{ Empresas } & IC & II & IA & Pontuação final \\
\hline Lojas Renner & 0 & 12 & 27 & 63 \\
Odontoprev & 3 & 4 & 32 & 59 \\
Bic Banco & 3 & 5 & 31 & 61 \\
Marcopolo & 3 & 16 & 20 & 83 \\
Springer Carrier & 4 & 5 & 30 & 65 \\
Plascar & 4 & 12 & 23 & 79 \\
Ambev & 6 & 11 & 22 & 85 \\
Souza Cruz & 6 & 12 & 21 & 87 \\
Unibanco & 7 & 12 & 20 & 91 \\
Whirlpool & 8 & 8 & 23 & 87 \\
Datasul & 10 & 9 & 20 & 97 \\
Braskem & 12 & 7 & 20 & 101 \\
Weg & 12 & 9 & 18 & 105 \\
Fras-le & 12 & 12 & 15 & 111 \\
Aracruz & 14 & 6 & 19 & 107 \\
Bradesco & 14 & 8 & 17 & 111 \\
Natura & 18 & 11 & 10 & 133 \\
AES Tietê & 20 & 3 & 16 & 125 \\
Ampla & 20 & 11 & 8 & 141 \\
AES Sul & 24 & 2 & 13 & 139 \\
CPFL Energia & 25 & 2 & 12 & 143 \\
Cemig & 25 & 6 & 3 & 155 \\
Coelce & 32 & 4 & $\mathbf{4 2 6}$ & 175 \\
\hline Totais & $\mathbf{2 8 2}$ & $\mathbf{1 8 9}$ & & $\mathbf{2 . 4 0 3}$ \\
\hline
\end{tabular}

Fonte: dados da pesquisa.

Destaca-se que a pontuação final é produto da multiplicação dos totais de IC, II e IA pelos seus respectivos pesos, conforme discriminado anteriormente no Quadro 2. Além disso, a pontuação final é proporcional a frequência maior de IC, ou seja, quanto mais IC uma empresa apresentou, maior sua pontuação final.

Constata-se pelos resultados apresentados na Tabela 2, no que concerne à pontuação obtida por empresa nas respectivas categorias de evidenciação, que apesar de muitas empresas apresentarem IC quanto às recomendações da NBC T 15, há predomínio de IA sobre as IC. Essas somaram 282 informações, enquanto que aquelas somaram 426, ou seja, as IA destacaram-se em torno de $50 \%$ a mais que as IC. Portanto, analisando-se o conjunto das empresas e as respectivas categorias de evidenciação, constata-se que as empresas estão de forma comedida divulgando as informações de cunho social de acordo com as recomendações da NBC T 15, pois nos três anos pesquisados as IA destacaram-se em relação às IC e II.

No grupo das empresas que evidenciaram mais IC, e consequentemente pontuaram mais, seis delas são do ramo de energia elétrica. Nesse grupo encontramse as empresas com menor e maior número de funcionários, sendo a CPFL com 240 e o Bradesco com 82.773. Dentre as empresas com maior número de IA, encontrase a Souza Cruz, sendo ela a mais antiga da amostra, enquanto que a Whirlpool, a empresa mais nova dentre elas.

A Coelce destaca-se como a empresa que evidenciou o maior número de IC, 
atingindo a marca de 32 informações, ou seja, 82\% de suas informações. Oposto a Coelce, tem-se a Odontoprev, que apresentou 32 IA e apenas 3 IC, ou seja, $82 \%$ de IA comparadas a apenas $7,7 \%$ de IC.

Do exposto, infere-se que o ramo de atividade talvez tenha influenciado na categorização da evidenciação social das empresas, pois se verificou maior concentração do ramo de energia elétrica na categoria de IC. É possível que esta situação decorra do maior nível de exigência com a transparência dessas empresas pelo órgão regulador específico. Por outro lado, não se constatou relação entre o número de funcionários e tempo de atividade das empresas, com as categorias de evidenciação social.

\subsection{COMPARAÇÃO DA PONTUAÇÃO DA EVIDENCIAÇÃO SOCIAL ENTRE 2005 E 2007}

Na comparação da pontuação da evidenciação social das empresas analisadas, considerando o ano de 2005 (período anterior) e o ano de 2007 (período posterior) da entrada em vigor da NBC T 15, apuraram-se os resultados constantes na Tabela 3.

Tabela 3 - Comparação da pontuação da evidenciação social das empresas entre 2005 e 2007

\begin{tabular}{|c|c|c|c|c|c|c|c|c|c|}
\hline \multirow{2}{*}{ Empresas } & \multicolumn{2}{|c|}{ IC } & \multicolumn{2}{|c|}{ II } & \multicolumn{2}{|c|}{ IA } & \multirow{2}{*}{$\begin{array}{c}\text { Pontuação } \\
\text { final } \\
2005\end{array}$} & \multirow{2}{*}{$\begin{array}{c}\text { Pontuação } \\
\text { final } \\
2007\end{array}$} & \multirow{2}{*}{$\%$} \\
\hline & 2005 & 2007 & 2005 & 2007 & 2005 & 2007 & & & \\
\hline Ampla & 9 & 2 & 3 & 4 & 1 & 7 & 55 & 29 & $-47 \%$ \\
\hline Weg & 5 & 2 & 3 & 3 & 5 & 8 & 39 & 27 & $-31 \%$ \\
\hline Datasul & 4 & 3 & 3 & 2 & 6 & 8 & 35 & 29 & $-17 \%$ \\
\hline Braskem & 3 & 3 & 3 & 2 & 7 & 8 & 31 & 29 & $-6 \%$ \\
\hline Aracruz & 5 & 4 & 2 & 3 & 6 & 6 & 37 & 35 & $-5 \%$ \\
\hline Fras-le & 4 & 4 & 5 & 4 & 4 & 5 & 39 & 37 & $-5 \%$ \\
\hline Cemig & 9 & 8 & 2 & 3 & 2 & 2 & 53 & 51 & $-4 \%$ \\
\hline Lojas Renner & 0 & 0 & 4 & 4 & 9 & 9 & 21 & 21 & $0 \%$ \\
\hline Marcopolo & 1 & 1 & 5 & 5 & 7 & 7 & 27 & 27 & $0 \%$ \\
\hline Odontoprev & 1 & 1 & 1 & 1 & 11 & 11 & 19 & 19 & $0 \%$ \\
\hline Plascar & 2 & 1 & 3 & 5 & 8 & 7 & 27 & 27 & $0 \%$ \\
\hline Souza Cruz & 2 & 2 & 4 & 4 & 7 & 7 & 29 & 29 & $0 \%$ \\
\hline Unibanco & 2 & 3 & 5 & 3 & 6 & 7 & 31 & 31 & $0 \%$ \\
\hline Coelce & 10 & 11 & 2 & 1 & 1 & 1 & 57 & 59 & $4 \%$ \\
\hline CPFL Energia & 8 & 9 & 1 & 0 & 4 & 4 & 47 & 49 & $4 \%$ \\
\hline Natura & 5 & 6 & 4 & 3 & 4 & 4 & 41 & 43 & $5 \%$ \\
\hline Ambev & 2 & 2 & 3 & 4 & 8 & 7 & 27 & 29 & $7 \%$ \\
\hline AES Sul & 7 & 8 & 1 & 1 & 5 & 4 & 43 & 47 & $9 \%$ \\
\hline AES Tietê & 6 & 8 & 1 & 1 & 6 & 4 & 39 & 47 & $21 \%$ \\
\hline Bradesco & 4 & 6 & 2 & 3 & 7 & 4 & 33 & 43 & $30 \%$ \\
\hline Whirlpool & 2 & 3 & 2 & 4 & 9 & 6 & 25 & 33 & $32 \%$ \\
\hline $\begin{array}{l}\text { S p r i n g e r } \\
\text { Carrier }\end{array}$ & 0 & 2 & 1 & 2 & 12 & 9 & 15 & 25 & $67 \%$ \\
\hline Bic Banco & 0 & 3 & 0 & 3 & 13 & 7 & 13 & 31 & $138 \%$ \\
\hline
\end{tabular}

Fonte: dados da pesquisa. 
Conforme dados da Tabela 3, sete empresas, 30,4\% delas, apresentaram queda na pontuação final de 2005 para 2007, principalmente pela redução de IC de um ano para outro, que é o caso da Ampla, Weg, Datasul, Aracruz e Cemig, enquanto que nas empresas Braskem e Fras-le, as IC se mantiveram inalteradas, ao passo que aumentou o número de IA.

Analisando-se as empresas que tiveram decréscimo de pontuação, destaca-se a empresa Ampla, com queda de $-47 \%$ de 2005 para 2007. Ela foi fundada em 1996, atua na produção e comercialização de energia elétrica, com quadro funcional de 8.652 pessoas.

Porém, seis empresas, $26,1 \%$ das pesquisadas, mantiveram a mesma pontuação final de 2005 para 2007, sendo que, quatro delas mantiveram a mesma quantidade de informação em cada categoria, exceto as empresas Plascar e Unibanco, em que se constataram alterações nas quantidades de informações em cada categoria.

Dentre as empresas que mantiveram a pontuação final de evidenciação, está a empresa Souza Cruz, mais antiga da amostra e atuante no ramo da fabricação de cigarros e exportação de fumo, contando com aproximadamente 6.700 empregados.

Das empresas analisadas, ressalta-se o grupo que apresentou acréscimo na pontuação final da evidenciação social, totalizando 10 empresas, 43,5\% do total. Destaca-se a empresa Bic Banco, que teve uma elevação de $138 \%$ da pontuação, passando de 13 pontos em 2005 para 31 pontos em 2007. É uma das empresas mais antigas e atua no ramo das instituições financeiras e emprega em torno de 823 funcionários.

Em síntese, dez empresas se destacaram pela melhora na evidenciação social, pois a pontuação final de 2007 aumentou em relação à obtida em 2005, principalmente pelo aumento de IC e redução de IA. Enquanto que seis delas mantiveram a evidenciação e sete delas tiveram a pontuação reduzida de 2005 para 2007, principalmente pela redução de IC e aumento de IA, o que impactou a pontuação final.

Mesmo que algumas empresas não alteraram e outras regressaram na pontuação final, aquelas que aumentaram a pontuação final obtiveram percentual de aumento superior ao percentual das empresas que tiveram a pontuação final reduzida, demonstrando que as empresas estão, ainda que de forma incipiente, buscando adequar a evidenciação social às recomendações da NBC T15.

\subsection{CLASSIFICAÇÃO DA EVIDENCIAÇÃO SOCIAL DAS EMPRESAS}

Após a categorização da evidenciação e atribuição da pontuação para cada uma das empresas, a pontuação obtida pelas empresas foi classificada em Insuficiente, Regular, Boa e Ótima, considerando a menor e a maior pontuação, conforme exposto 
no Quadro 3 anteriormente. Sobre a classificação da evidenciação social das empresas pesquisadas no período de 2005 a 2007, apresentam-se os resultados na Tabela 4.

Tabela 4 - Classificação da evidenciação social das empresas

\begin{tabular}{|c|c|c|c|c|}
\hline Quartis & Classificação & Pontuação final & Empresas & $100 \%$ \\
\hline & Insuficiente & 59 & Odontoprev & \\
\hline $1^{\circ}$ & Insuficiente & 61 & Bic Banco & \multirow{3}{*}{$17,4 \%$} \\
\hline \multirow{2}{*}{ (39 a 78 pontos) } & Insuficiente & 63 & Lojas Renner & \\
\hline & Insuficiente & 65 & Springer Carrier & \\
\hline \multirow{12}{*}{$\begin{array}{c}2^{\circ} \\
\text { (79 a } 117 \text { pontos) }\end{array}$} & Regular & 79 & Plascar & \multirow{12}{*}{$52,2 \%$} \\
\hline & Regular & 83 & Marcopolo & \\
\hline & Regular & 85 & Ambev & \\
\hline & Regular & 87 & Souza Cruz & \\
\hline & Regular & 87 & Whirlpool & \\
\hline & Regular & 91 & Unibanco & \\
\hline & Regular & 97 & Datasul & \\
\hline & Regular & 101 & Braskem & \\
\hline & Regular & 105 & Weg & \\
\hline & Regular & 107 & Aracruz & \\
\hline & Regular & 111 & Bradesco & \\
\hline & Regular & 111 & Fras-le & \\
\hline \multirow{6}{*}{$\begin{array}{c}3^{\circ} \\
\text { (118 a } 156 \text { pontos) }\end{array}$} & Boa & 125 & AES Tietê & \multirow{6}{*}{$26,1 \%$} \\
\hline & Boa & 133 & Natura & \\
\hline & Boa & 139 & AES Sul & \\
\hline & Boa & 141 & Ampla & \\
\hline & Boa & 143 & CPFL Energia & \\
\hline & Boa & 155 & Cemig & \\
\hline $4^{\circ} \quad(157$ a 195$)$ & Ótimo & 175 & Coelce & $4,3 \%$ \\
\hline
\end{tabular}

Fonte: dados da pesquisa.

Conforme se demonstra na Tabela 4, quatro empresas, 17,4\% delas, Odontoprev, Bic Banco, Lojas Renner e Springer Carrier, obtiveram o conceito Insuficiente quanto ao nível de evidenciação social, tendo em vista que sua soma de pontos ficou entre 59 e 65. Esse resultado se deve principalmente pelo predomínio de informações ausentes (IA) quanto à categorização da evidenciação social de acordo com a NBC T 15.

Perfazendo o maior grupo, 52,2\% das empresas, ou seja, doze delas, obtiveram o conceito Regular, Plascar, Marcopolo, Ambev, Souza Cruz, Whirlpool, Unibanco, Datasul, Braskem, Weg, Aracruz, Bradesco e Fras-le, já que atingiram pontos que variaram de 79 a 111, resultado decorrente principalmente pelo predomínio de informações incompletas (II) e ausentes (IA) quanto a categorização da evidenciação social de acordo com a NBC T 15.

Outras seis empresas, 26,1\% delas, AES Tietê, Natura, AES Sul, Ampla, CPFL e Cemig, pontuaram entre 125 a 155, o que as coloca no nível de evidenciação Boa, devido ao predomínio de informações completas (IC) quanto à categorização da evidenciação social de acordo com a NBC T 15. 
No entanto, representando $4,3 \%$ do total das empresas, somente a Coelce apresentou excelente nível de evidenciação social, o que a tornou a única empresa a atingir o conceito Ótimo, tendo sua soma de pontos no patamar de 175, quando a pontuação máxima que uma empresa poderia atingir é de 195 pontos. Assim, a Coelce destaca-se em relação às demais, por ter ficado apenas 20 pontos abaixo do nível máximo de evidenciação.

É válido ressaltar que dentre as 23 empresas analisadas, todas as empresas pertencentes ao ramo de energia elétrica, AES Sul, AES Tietê, Ampla, Cemig, e CPFL, classificaram-se no conceito Bom, com exceção da Coelce que obteve conceito Ótimo, quanto ao seu nível de evidenciação.

Tal classificação talvez tenha sido influenciada pelo fato de que algumas das empresas que apresentaram acréscimo na pontuação final, comparando-se o ano de 2005 com 2007, também classificaram sua evidenciação social como Ótima ou Boa, como é o caso das empresas AES Tietê, Natura, AES Sul, CPFL Energia e Coelce. Somente as empresas Ampla e Cemig tiveram decréscimo na pontuação final, mantendo apesar disso, boa classificação na evidenciação social.

\section{CONSIDERAÇÕES FINAIS}

Objetivou-se com o estudo averiguar se a evidenciação social no relatório da administração e notas explicativas das empresas de capital aberto está adequada às recomendações da NBC T 15, comparando-se o exercício social de 2005, ano anterior e o exercício social de 2007, ano posterior a entrada em vigor da referida norma.

No que se refere à caracterização das empresas pesquisadas de capital aberto, listadas na Revista Exame 150 Melhores Empresas para Você Trabalhar, edição especial 2007, constatou-se que, dentre as 23 empresas pesquisadas, a Souza Cruz destaca-se em tempo de atividade, sendo a única empresa centenária, enquanto que a empresa Whirlpool apresenta-se como a mais nova entre as analisadas. 0 ramo de energia elétrica, no qual se concentram seis empresas, destaca-se entre os demais ramos de atividades. Na análise do número de funcionários, outro ramo ficou em evidência, o das instituições financeiras, por ser o maior empregador de mão-de-obra.

Quanto à categorização da evidenciação social das empresas no período de 2005 a 2007, segundo o checklist baseado na NBC T 15, os resultados revelam que a empresa Coelce se destacou das demais como a empresa que evidenciou o maior número de suas IC, em que se constaram 32 informações evidenciadas de forma completa. A Marcopolo, por sua vez, destacou-se por apresentar 16 II, o maior número dentro dessa categoria, enquanto que a Odontoprev apresentou 32 IA. Ressalta-se que as empresas poderiam atingir até 39 pontos distribuídos entre IC, II e IA, nos três anos 
analisados, que é a soma de 13 informações buscadas em cada ano pesquisado.

Comparando-se a pontuação final da evidenciação social das empresas analisadas, considerando o ano de 2005 (período anterior) e o ano de 2007 (período posterior) da entrada em vigor da NBC T 15, constatou-se que dez empresas apresentaram acréscimo de informações de caráter social, com destaque à empresa Bic Banco, com 138\% de aumento, pois a pontuação final de 2007 aumentou em relação à obtida em 2005, principalmente pelo aumento de IC e redução de IA. Seis delas mantiveram a evidenciação, enquanto que sete delas apresentaram queda na pontuação final, sendo a Ampla a empresa que apresentou o maior percentual, com $47 \%$ de decréscimo, principalmente pela redução de IC e aumento de IA, o que impactou a pontuação final.

Sobre a classificação da evidenciação social das empresas pesquisadas no período de 2005 para 2007, no tocante à qualidade das informações conforme a pontuação final obtida, notou-se que, das 23 empresas, doze delas tiveram sua evidenciação social classificada como Regular, sendo esta a classificação que predominou entre todas as empresas. Depois, vem o grupo de seis empresas, classificadas com evidenciação social Boa em relação às recomendações da NBC T 15, seguida por quatro empresas, classificadas como evidenciação Regular; ao passo que somente a Coelce teve sua evidenciação classificada como Ótima. Ou seja, apesar do acréscimo na pontuação final quanto à evidenciação social obtida pela maioria das empresas pesquisadas, a classificação da evidenciação social das empresas é predominantemente Regular, ficando aquém do ideal que seria Boa para Ótima.

Conclui-se que a evidenciação social no relatório da administração e notas explicativas das 23 empresas de capital aberto analisadas não está adequada às recomendações da NBC T 15, quando comparada a evidenciação social do ano de 2005 com a evidenciação social do ano de 2007. Apesar do aumento de informações consideradas completas de um ano para outro, há predomínio da classificação Regular da evidenciação social consoante a NBC T 15.

Recomenda-se, com base nas limitações deste estudo, reaplicar a pesquisa em empresas de capital fechado, listadas na Revista Exame 150 Melhores Empresas para Você Trabalhar. Sugere-se também efetuar um estudo nas mesmas empresas, porém com enfoque na evidenciação ambiental para averiguar a adequação das informações às recomendações da NBC T 15 e fazer um comparativo com a evidenciação social aqui investigada. 


\section{REFERÊNCIAS}

BEUREN, Ilse Maria, BOFF, Marines Lucia. Evidenciação de termos ambientais e sociais em relatórios da administração de empresas familiares brasileiras. In: Colóquio Internacional sobre Poder Local, 11., 2009, Salvador-Bahia. Anais... Salvador-Bahia, 2009.

BEUREN, Ilse Maria; BOFF, Marines Lucia; HEIN, Nelson. Informações recomendadas pelo Parecer de Orientação $n^{\circ} 15 / 87$ da CVM nos relatórios da administração de empresas familiares de capital aberto. In: CONGRESSO USP DE CONTROLADORIA E CONTABILIDADE, 8., 2008, São Paulo. Anais ... São Paulo: FEA/USP, 2008.

Bolsa de Valores de São Paulo (BOVESPA). Disponível em: <http: / /www.bovespa.com. br>. Acesso em: 13 abr. 2008.

BRASIL. Lei $n^{\circ}$ 6.404, de 15 de dezembro de 1976. Lei das Sociedades por Ações. Diário Oficial [da] República Federativa do Brasil, Brasília, DF, 17 dez. 1976. Disponível em: <http://www.cnb.org.br/CNBV/leis/lei6404_consolidada.htm>. Acesso em: 03 maio 2008.

CAVALCANTI, Gabriella Holanda; ALMEIDA, Karla Katiuscia Nóbrega de; ALMEIDA, Sílvio Romero de; LIMEIRA, Marizelma Patriota. Um estudo sobre o grau de aderência normativa da divulgação de informações contábeis ambientais das empresas brasileiras do setor de utilidade pública. In: South American Congress on Social and Environmental Accounting Research - CSEAR, $1^{\text {st }}$, , 2009, Rio de Janeiro - Brasil. Disponível em: <http://www.facc.ufrj.br/csear2009/15.pdf>. Acesso em: 11 dez. 2009.

COMISSÃO DE VALORES MOBILIÁRIOS. Parecer de orientação $n^{\circ}$ 15, de 28 de dezembro de 1987. Disponível em: <http://www.cvm.gov.br>. Acesso em: 10 jul. 2008.

CONSELHO FEDERAL DE CONTABILIDADE. Disponível em: < http://www.cfc.org.br>. Acesso em: 13 abr. 2008.

DIAS FILHO, José Maria. Políticas de evidenciação contábil: um estudo do poder preditivo e explicativo da teoria da legitimidade. In: EnANPAD, 31., 2007, Rio de Janeiro. Anais... Rio de Janeiro: ANPAD, 2007. CD-ROM.

DIMAGGIO, Paul J.; POWELL, Walter W. A gaiola de ferro revisitada: isomorfismo institucional e racionalidade coletiva nos campos organizacionais. Clássicos. RAE Revista de Administração de Empresas (online), v. 45, n. 2, p. 74-89, abr/ jun. 2005.

FARIA, Ana Cristina de; OLIVEIRA, Robson de. Evidenciação de eventos econômicos 
de natureza ambiental pelas empresas do setor químico e petroquímico. In: SEGET SIMPÓSIO DE EXCELÊNCIA EM GESTÃO E TECNOLOGIA, 3., 2006, Rezende/RJ. Anais... Resende: SEGET, 2006. CD-ROM.

FARIA, Ana Cristina de; PEREIRA, Raquel da Silva. Disclosure de informações socioambientais pelas maiores empresas do segmento químico e petroquímico no Brasil, a partir da NBC T -15. In: EnANPAD, 33., 2009, São Paulo. Anais... Rio de Janeiro: ANPAD, 2009. CD-ROM.

GAMBOA, Sílvio Sanches. Quantidade-qualidade: para além do dualismo técnico e de uma dicotomia epistemológica. In: SANTOS FILHO, José Camilo dos; GAMBOA, Sílvio Sanches. Pesquisa educacional: qualitativa-quantitativa. São Paulo: Cortez, 1995. p. 106.

GAO, Simon S.; HERAVI, Saeed; XIAO, Jason Zezheng. Determinants of corporate social and environmental reporting in Hong Kong: a researsh note. Accounting Forum, v. 29, p. 233-242, 2005.

GIL, Antonio Carlos. Como elaborar projetos de pesquisa. 4. ed. São Paulo: Atlas, 2002.

LINDBLOM, C. K. The implications of organizational legitimacy for corporate social performance and disclosure. In: Critical Perspectives on Accounting Conference. New York, 1994.

MAZZIONI, Sady; TINOCO, João Eduardo Prudêncio. Balanço social para uma fundação universitária. In: CONGRESSO USP DE CONTROLADORIA E CONTABILIDADE, 5., 2005, São Paulo. Anais ... São Paulo: FEA/USP, 2005. CD-ROM.

PARSA, Sepideh; KOUHY, Reza. Disclosure of social information by UK companies: a case of legitimacy theory. September/2001. Disponível em: <http://mubs.mdx. ac.uk/research/Discussion_Papers/Accounting_and_Finance>. Acesso em: 04 abr. 2007.

REVISTA VOCÊ S/A - EXAME. 150 melhores empresas para você trabalhar. São Paulo. Ed. especial, 13 set. 2007. 274p.

ROVER, Suliani; ALVES, Jorge Luiz; BORBA, José Alonso. A evidenciação do passivo ambiental: quantificando o desconhecido. In: CONGRESSO USP DE CONTROLADORIA E CONTABILIDADE, 5., 2005, São Paulo. Anais... São Paulo: FEA/USP, 2005. CD-ROM.

SANCOVSCHI, Moacir; SILVA, Adolfo Henrique Coutinho e. Evidenciação social corporativa: estudo de caso da empresa Petróleo Brasileiro S.A. Revista Sociedade, Contabilidade e Gestão, Rio de Janeiro, v. 1, n. 1, $2^{\circ}$ semestre, 2006.

VELOSO, Letícia Helena Medeiros. Ética, valores e cultura: especificidades do conceito 
de responsabilidade social corporativa. In: ASHLEY, Patrícia Almeida (coord.). Ética e responsabilidade social nos negócios. 2. ed. São Paulo: Saraiva. 2006.

VIEIRA, Marli Terezinha, FARIA, Ana Cristina de. Aplicação da NBC T 15 por empresas dos segmentos de bebidas e alimentos: uma pesquisa documental. Revista Universo Contábil, Blumenau, v.3, n. 1, p. 49-69, jan./abr. 2007.

VIEIRA, Marli Terezinha. Evidenciação de informações de responsabilidade social na maior empresa em cada segmento da economia brasileira. 2006. 136 f. Dissertação (Mestrado em Ciências Contábeis) - Curso de Pós-Graduação em Ciências Contábeis, Universidade Regional de Blumenau, Blumenau, 2006. 


\section{ENDEREÇOS DOS AUTORES:}

Ilse Maria Beuren

Universidade Regional de Blumenau

Centro de Ciências Sociais e Aplicadas

R. Antonio da Veiga, 140, sala D 202 - Victor Konder

Caixa-Postal: 1507

Blumenau, SC - Brasil

89012-900

\section{Marines Lucia Boff}

Universidade do Oeste de Santa Catarina.

Rua Oiapoc, 211 Agostini

Caixa-Postal: 391

São Miguel D’Oeste, SC - Brasil

89900-000

\section{Juliane Elisabeth Horn}

Universidade do Oeste de Santa Catarina.

Rua Oiapoc, 211 Agostini

Caixa-Postal: 391

São Miguel D’Oeste, SC - Brasil

89900-000

\section{Marciane Angela Horn}

Universidade do Oeste de Santa Catarina.

Rua Oiapoc, 211 Agostini

Caixa-Postal: 391

São Miguel D’Oeste, SC - Brasil

89900-000 